\title{
sciendo
}

CIVIL AND ENVIRONMENTAL ENGINEERING REPORTS

E-ISSN 2450-8594

CEER 2020; 30 (2): 0158-0184

DOI: $10.2478 /$ ceer-2020-0025

Original Research Article

\section{A STUDY OF THE DURABILITY OF CONCRETE REINFORCED WITH HEMP FIBERS EXPOSED TO EXTERNAL SULFATIC ATTACK}

\author{
Sami ZIANE ${ }^{1}$, Mohammed-Rissel KHELIFA ${ }^{2}$, Samy MEZHOUD $^{3 *}$ \\ ${ }^{1} \mathrm{Ph} . \mathrm{D}$. student, Laboratory of Soil Mechanics and structures (LMSS), Dept. of Civil \\ Engineering, Faculty of Science and Technology, University of Mentouri Brothers \\ Constantine 1, Constantine, Algeria \\ ${ }^{2}$ Department of Civil Engineering, Faculty of Technology, University of Batna 2, Batna, \\ Algeria \\ ${ }^{3}$ Department of Geography and Land Sciences, University of Mentouri Brothers \\ Constantine1, Constantine, Algeria
}

\begin{abstract}
The purpose of this paper is to study the durability of concrete reinforced with hemp fibers in the face of external Sulfatic attack. For this purpose, five types of concrete were formulated; three types of concrete reinforced with hemp fibers (HC-0.25, HC-0.5, and HC- 1 ) at $0.25 \%, 0.5 \%$, and $1 \%$ of hemp fibers in volume, respectively. And two control concretes, being ordinary concrete (OC) and polypropylene fiber reinforced concrete (PC). To assess the sulfatic attacks, the described concrete types underwent two aging protocols: 1) a complete immersion in $12.5 \%$ Sodium Sulfate $\left(\mathrm{Na}_{2} \mathrm{SO}_{4}\right)$ solution, and 2$)$ an accelerated aging protocol consisting of immersion/drying in the same sulfate solution at a temperature of $60^{\circ} \mathrm{C}$. The results show that concrete reinforced with $0.25 \%$ of hemp fibers is the optimal amount compared to control concretes in terms of physicomechanical performance and durability under sulfate attack. This number of fibers could enable the production of green and durable structural concretes based on untreated hemp fibers.
\end{abstract}

\footnotetext{
${ }^{1}$ Corresponding author: Department of Geography and Land Sciences, University of Mentouri Brothers Constantine1, Constantine, Algeria. e-mail: mezhoud.sami@umc.edu.dz
} 
Keywords: reinforced concrete, hemp fibers, polypropylene fibers, mechanical performance, sulfatic attacks

\section{INTRODUCTION}

Concrete is the most widely used construction material today. It has an annual consumption of more than 25 billion tons [1]. It is an economic material with good compressive strength. However, concrete has a low tensile strength, which is typically around 5 to $8 \%$ of its compressive strength and, therefore, it has low toughness [2, 3].

The durability of concrete has become a major issue in structural engineering over the last decades and is affected by both internal and external factors. This lack of durability can lead to premature failure and/or reduced serviceability. For this reason, this issue has become a major concern in developing sustainable infrastructure systems [4]. The alteration of structural concrete elements due to the action of external chemical degrading agents is one of the main causes of the reduction of the service life in modern constructions [5]. Among the various forms of degradation, sulfatic attacks present one of the main mechanisms in concrete. The interaction of cementitious materials with solutions containing sulfate present in groundwater, seawater, soils, and wastewaters leads to the formation of Gypsum, Ettringite and/or Thaumasite, and may cause cracking patterns, spalling, softening, expansion, loss of strength, and other forms of damage [6,7]. The results of external sulfatic attacks are often related to the appearance of cracks due to changes in volume or the expansive nature of the reaction products [8]. To overcome these problems, reinforcing fibers can be incorporated into the concrete in various civil engineering applications [9].

Fibers have been widely used since the beginning of the 20th century to improve a variety of properties such as flexural strength, stiffness, impact, fatigue, abrasion, deformability, ductility characteristics, and durability of concrete $[10,11]$. The main advantage of the use of fibers is better control of the cracking pattern [12]. Furthermore, when incorporating fibers into cement-based materials, cracking due to plastic shrinkage and drying shrinkage of the material as well as its permeability could be considerably reduced [13]. There are many kinds of fibers widely used in concrete engineering for their various advantages $[14,15]$. Examples are artificial fibers such as steel fibers or synthetic fibers such as polypropylene fibers. On the other hand, there are natural fibers, whether from animals such as alpaca fibers [16] or plants such as Alfa and Hemp fibers. Steel and polypropylene fibers are the most commonly used reinforcing fibers $[17,18]$; however, despite their advantages, the high cost of the raw material, the expensive and non-environmentally friendly manufacturing process ( the release of $\mathrm{CO}_{2}$ through their production) have prompted researchers and industries to 
substitute them with chemically untreated plant fibers for the production of more economical, sustainable, and environmentally friendly concrete $[19,20]$.

Vegetable fibers are generally characterized by a complex microstructure but with satisfactory mechanical performance, in particular, their tensile strength is generally above $200 \mathrm{MPa}$ [21]. In addition, they offer several advantages such as availability, recyclability, low cost, environmentally friendly character, no toxicity, no abrasion, and biodegradability [22]. Numerous plant fibers have been studied to evaluate the potential for enhancing concrete such as jute, date palm, bamboo, dis, and alfa to produce eco-friendly housing and infrastructure in both urban and rural areas. Despite all this, very few research studies have focused on the durability of concretes based on these natural fibers.

Hemp fiber is mainly used in construction for sound and heat insulation. Hemp is an annual herbaceous plant of Asian origin, cultivated by man for more than a thousand years. It belongs to the Cannabinaceae family, reaches a height of up to 4 meters, and is cultivated particularly in countries with a temperate climate, such as France, Spain, and Canada [23]. The hemp plant has been characterized by its rapid growth, high production of dry biomass, and high carbon storage potential [24]. In addition, this plant does not need the use of pesticides or amendment and grows in perfect harmony with its environment. Hemp fibers were originally used in the textile, food, automotive, and paper industries as well as in building insulation. These fibers have increasingly aroused the interest of researchers in recent years because of their very interesting physico-mechanical characteristics [25]. In literature, several studies were performed on hemp reinforced concretes, however, these studies have focused only on the appropriate formulation method [26, 27]. The durability of hemp fiber reinforced concrete is important and not yet well studied.

In this paper, we pay particular attention to the effect of hemp fibers on the physical and mechanical properties of reinforced concrete compared to an ordinary concrete (OC) and a concrete reinforced with polypropylene fibers (PC) to evaluate the production of more environmentally friendly concretes. To this end, different amounts of hemp fibers, respectively $0.25 \%, 0.5 \%$, and $1 \%$, were added to the concrete mixture in order to determine the optimal concentration of fibers to obtain a suitable structure of concrete. Compression and tensile strength tests were performed together with Young's modulus variations and physical tests. In addition, the durability of these concretes against sulfatic attacks was also studied using two aging protocols: 1) a complete immersion in $\mathrm{Na} 2 \mathrm{SO} 4$ solution with a concentration of $12.5 \%$ by weight [28], and 2) the use of an accelerated aging protocol; immersion/drying at $60^{\circ} \mathrm{C}$ in the same solution with the same concentration [29]. 


\section{MATERIALS}

\subsection{Fibers}

The hemp plant (Cannabis sativa L) used in this research is categorized as a bast fiber crop. It provides three co-products: the seed, the fiber, and the goosefoot [30]. Hemp fibers (Figure 1a) are obtained from the outer part of the stem by a mechanical threshing process. The process of hemp fiber extraction consists of several steps: harvesting, retting in the field, and exploitation of the hemp straw [31]. To begin with, the long hemp fibers were cut into the desired lengths, being $20 \mathrm{~mm}$ for this study. Table 1 shows the physico-chemical characteristics of hemp fibers [23, 24, and 32].

The polypropylene fibers (Figure 1b) were TUF-STRAND MAXTEN brand fibers, manufactured according to ASTM C 1116, Standard Specification for Fiber Reinforced Concrete and Shotcrete. They were also about $20 \mathrm{~mm}$ in length. Table 2 gives their characteristics.

Table 1. Physical, chemical, and mechanical characteristics of Hemp fibers

\begin{tabular}{lrr}
\hline Chemical composition (\%) & Cellulose: & 56.1 \\
& Hemicellulose: & 10.9 \\
& Lignins: & 6.0 \\
& Pectin: & 20.1 \\
\hline Tensile strength (MPa) & $59-857$ \\
Young's modulus $(\mathrm{GPa})$ & $38-58$ \\
Density $\left(\mathrm{kg} / \mathrm{m}^{3}\right)$ & 1400 \\
Porosity $(\%)$ & $180-105$ \\
Diameter $(\mu \mathrm{m})$ & $16-50$ \\
\hline Table 2. Characteristics of Polypropylene fibers & \\
\hline Parameters & Value \\
\hline Mass density (kg/m $\left.{ }^{3}\right)$ & 910 \\
The amount of polypropylene (\%) & $1.8-3$ \\
Young's modulus (MPa) & $3500-3900$ \\
Tensile strength $(\mathrm{MPa})$ & $600-650$ \\
Melting point $\left({ }^{\circ} \mathrm{C}\right)$ & 165 \\
Water absorption $(\%)$ & negligible \\
\hline
\end{tabular}



FIBERS EXPOSED TO EXTERNAL SULFATE ATTACK

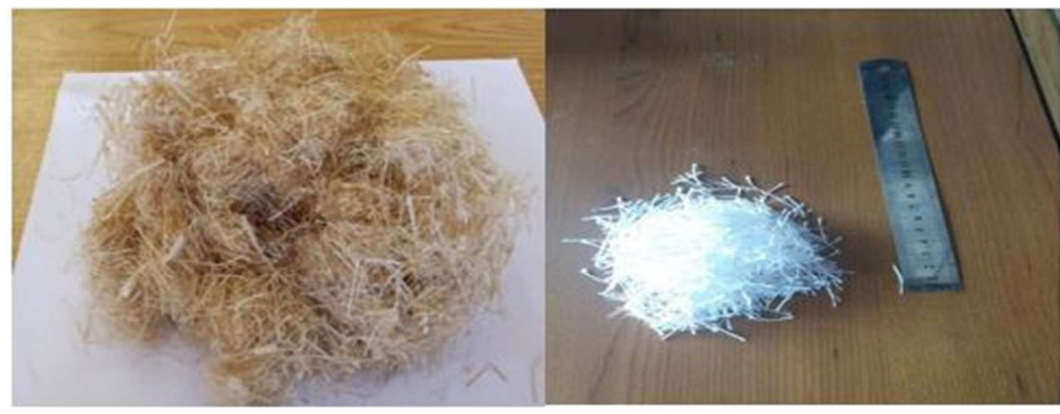

a) Hemp fibers

b) Polypropylene fibers

Fig 1. Fibers used for the concrete reinforcement

\subsection{Cement}

The cement used for all mixtures was a Portland Composite Cement (CEM II/A 42.5) with a density of $3.06 \mathrm{~g} / \mathrm{cm} 3$ and Blaine fineness of $3891 \mathrm{~g} / \mathrm{cm} 2$, conforming to European standard EN 197-1 [33]. The chemical composition of the cement is given in Table 3. Application of Bogue's formulas to the chemical composition of the cement gave the following mass distribution of the main phases: $59,66 \%$ of $\mathrm{C} 3 \mathrm{~S}, 16,45 \%$ of $\mathrm{C} 2 \mathrm{~S}, 9,14 \%$ of $\mathrm{C} 3 \mathrm{~A}$, and $11,02 \%$ of C4AF.

Table 3. Chemical composition of the cement.

\begin{tabular}{lr}
\hline Cement & Content (\%) \\
\hline $\mathrm{SiO}_{2}$ & 23.25 \\
$\mathrm{Al}_{2} \mathrm{O}_{3}$ & 5.69 \\
$\mathrm{Fe}_{2} \mathrm{O}_{3}$ & 3.36 \\
$\mathrm{CaO}$ & 60.25 \\
$\mathrm{MgO}$ & 0.74 \\
$\mathrm{SO}_{3}$ & 1.94 \\
$\mathrm{~K}_{2} \mathrm{O}$ & 0.45 \\
$\mathrm{Na}_{2} \mathrm{O}$ & 0.27 \\
Equivalent $\mathrm{Na}_{2} \mathrm{O}$ & 0.98 \\
\hline
\end{tabular}

\subsection{Aggregates}

All aggregates used are calcareous (limestone), and the petrographic analysis shows that the rocks are mainly calcite $\left(\mathrm{CaCO}_{3}\right), 94 \%$, and $6 \%$ dolomite $\left(\mathrm{CaMg}\left(\mathrm{CO}_{3}\right)_{2}\right)$. The sand is $0 / 3 \mathrm{~mm}$, with a specific gravity of $1440 \mathrm{~kg} / \mathrm{m} 3$ and a water absorption coefficient of $0.78 \%$ (in mass). The coarse aggregates are $3 / 8$ $\mathrm{mm}$ and $8 / 16 \mathrm{~mm}$, with a specific gravity of $1350 \mathrm{~kg} / \mathrm{m} 3$ and a water absorption coefficient of $0.72 \%$ (in mass). The size distribution graphs of all aggregates are given in Figure 2. 


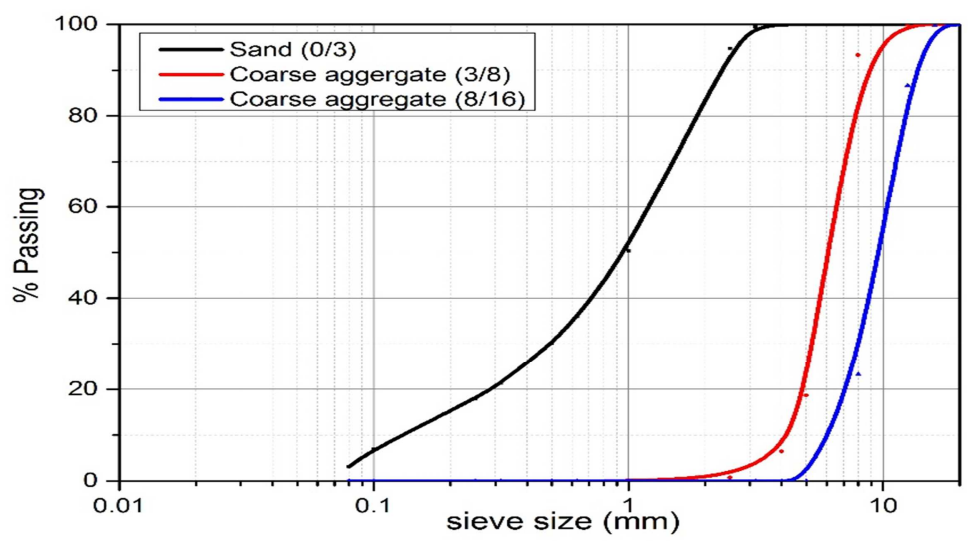

Fig 2. Particle size distribution of sand and coarse aggregate

\subsection{Superplasticizer}

One type of chemical admixture (SUPERIOR RM 34) was used for all mixes to provide better workability in the fresh state. This superplasticizer is based on modified silicate polycarbons and is compatible with all types of cements. It is an Ether solution with a specific gravity of 1.1 at $25 \mathrm{C}^{\circ}$ and it complies with EN934-2 [34].

\section{EXPERIMENTAL PROGRAM AND TESTS CARRIED OUT}

\subsection{Mix design}

In this study the followings concrete mixes were prepared: 1) Three concretes incorporating hemp fibers (HC-0.25; HC-0.5; HC-1), respectively, 0.25, 0.5, and $1 \%$ of hemp fibers by volume, 2 ) a concrete incorporating $0.25 \%$ by volume of polypropylene fibers (PC) and 3 ) an ordinary concrete (OC) used as reference material. All mix proportions are detailed in Table 4.

The fibers, whatever their nature, were incorporated into the concrete mixture as an additional component and not as a substitute for any other component such as aggregates. Different quantities of hemp fibers were tested in order to determine the ideal amount for the concrete. The concentration of $0.25 \%$ is similar to that recommended by the manufacturer for the use of polypropylene fibers, which allows a direct comparison of the mechanical properties between the different composites. In addition, they were mixed with the aggregates and cement before adding the water to guarantee uniform dispersion, which is deal with the reinforcement capacity. 
Table 4. Concrete mix designs

\begin{tabular}{llllll}
\hline & \multicolumn{5}{l}{ Mix code } \\
\cline { 2 - 6 } Mix proportion for $1 \mathrm{~m}^{3}$ & OC & PC & HC-0.25 & HC-0.5 & HC- 1 \\
\hline Cement $\left(\mathrm{kg} / \mathrm{m}^{3}\right)$ & 350 & 350 & 350 & 350 & 350 \\
Sand 0/3 $\mathrm{mm}\left(\mathrm{kg} / \mathrm{m}^{3}\right)$ & 727 & 727 & 727 & 727 & 727 \\
Coarse $3 / 8 \mathrm{~mm}\left(\mathrm{~kg} / \mathrm{m}^{3}\right)$ & 109 & 109 & 109 & 109 & 109 \\
Coarse $8 / 16 \mathrm{~mm}\left(\mathrm{~kg} / \mathrm{m}^{3}\right)$ & 897 & 897 & 897 & 897 & 897 \\
Superplasticizer $(\%)$ & 0,6 & 0,6 & 0,6 & 2 & 2 \\
Water $\left(\mathrm{kg} / \mathrm{m}^{3}\right)$ & 140 & 140 & 140 & 140 & 140 \\
Hemp fibers $(\%)$ & - & - & 0.25 & 0.50 & 1.00 \\
Polypropylene fibers $(\%)$ & - & 0.25 & - & - & - \\
\hline
\end{tabular}

\subsection{Experimental program}

After dry and humid mixing of the different components in a mixer with a vertical axis and planetary motion, fresh and hardened tests were carried out;

- For the fresh tests, the slump test was used to quantify the workability of the concrete according to the standard NF EN 12350-2 [35], and the density of the concrete in the fresh state was measured according to the standard NF EN 12350-6 [36].

- For each concrete mixture, cylindrical specimens $(10 \mathrm{x} 20 \mathrm{~cm})$ for compressive tests and prismatic specimens $(7 \times 7 \times 28 \mathrm{~cm})$ for compressive and tensile strength tests, respectively, were prepared. After casting, all the specimens were moist-cured at $20 \pm 2{ }^{\circ} \mathrm{C}$ and $50 \pm 5 \%$ of relative humidity until the age of testing $(7,28,90$, and 120 days).

- In the hardened state, the characterization of mixes was carried out by the following methods and according to the standards. For each test and age, the measures were carried out on three specimens for all mixes, and the average values are reported. The tensile and compressive strengths were determined according to the NF P15-471[37]; the dynamic Young's modulus was measured according to NF P 18-414[38], the open porosity and capillary absorption of the concretes was determined using a procedure based on that recommended by AFPC-AFREM [39]. 


\subsection{Sulfatic attacks protocols}

\subsubsection{Complete immersion}

This protocol is the most frequently used in the literature to simulate a sulfatic attack on concrete in saline soils such as gypsum [40]. The cubic specimens $(7 \times 7 \times 7 \mathrm{~cm})$ of concrete are completely immersed in a $12.5 \%$ by weight Sodium Sulfate $\left(\mathrm{Na}_{2} \mathrm{SO}_{4}\right)$ solution at $20^{\circ} \mathrm{C}$, renewed every 30 days.

To monitor the behavior of samples subjected to sulfatic attack over time, the mass loss monitoring was selected at different time intervals over a period of 270 days. For the compressive strength of different concretes, measurements were taken after 28 days of normal cure and after 45 days, 90 days, 180 days, and 270 days of total immersion.

\subsubsection{Immersion/ drying cycles at $60^{\circ} \mathrm{C}$}

A protocol for accelerating the aging of concrete based on 24-hour immersion cycles $[26,41]$. It is defined as follows:

- Immersion (4 hours) of the specimens in a $12.5 \%$ Sodium Sulfate $\left(\mathrm{Na}_{2} \mathrm{SO}_{4}\right)$ solution by mass.

- Drying (20 hours) in an oven at $60^{\circ}$. This temperature level was selected to avoid the superposition with the internal sulfatic attack from the delayed formation of Ettringite [42, 43, and 44].

Daily, the mass of each sample was measured after the drying phase. The samples were tested with a compression test after 28 days of normal cure and at $05,15,30$, and 60 cycles of immersion to follow the evolution of their mechanical performance.

\section{RESULTS AND DISCUSSION}

\section{1. The slump test}

The results of the slump test are presented in Figure 3. Two groups of concrete can be distinguished: 1) Very plastic concretes class S3 (110 - $140 \mathrm{~mm})$ : OC, HC-0.25 and PC concretes, and 2) Stiff concretes S1 (50 mm): HC -0.5 and HC1. It can be seen that the incorporation of hemp fibers leads to a decrease in concrete slump, reflecting a reduction of workability. This finding can be explained by the high porosity of the hemp fibers, which absorb a large amount of mixing water. The decrease in porosity is observed to be proportional to the fiber amount. These results are consistent with previous studies on the impact of plant fibers on the slump of cementitious composites [45, 46, and 47]. It should 
be noted that the superplasticizer was added to the mixes to maintain the level of workability and to obtain a structural concrete that is easy to place.

No significant change in the workability of HC- 0.5 and $\mathrm{HC}-1$ concretes was observed despite the dosage of the superplasticizer. They remained in the range of stiff concretes because the plant fibers have lower rigidity than conventional fibers, which leads to the formation of balls during hydration and mixing (socalled balling' Phenomenon), as confirmed in the literature [48,49]. In the case of the PC concretes, there is a slight reduction in slump caused by the amount of water remaining on the surfaces of the polypropylene fibers, although these fibers do not absorb water, a small amount is retained by the surface of the fibers.

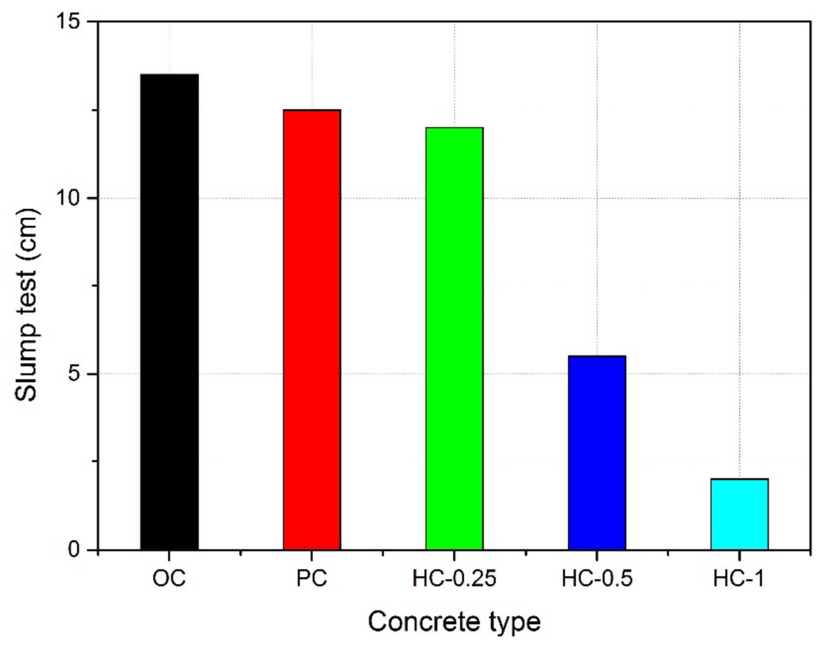

Fig 3. Slump test results of made-up concretes

\section{2. The fresh density}

The density results of each concrete are $2376.3 \mathrm{~kg} / \mathrm{m} 3$ for OC, $2367.1 \mathrm{~kg} / \mathrm{m} 3$ for PC, $2353 \mathrm{~kg} / \mathrm{m} 3$ for HC- $0.25,2331.2 \mathrm{~kg} / \mathrm{m} 3$ for HC- 0.5 , and $2291.1 \mathrm{~kg} / \mathrm{m} 3$ for HC-1.

We can observe that the incorporation of hemp fibers in the concrete mixes significantly affected this factor by increasing the content of voids under the effect of the entrapped air, especially when their dosage increased. This could be due to the high fiber content, which creates more pores and reduces pulp content and density in the fresh state as well as poor dispersion of the fibers when their percentage by volume is high. The results also show a slight difference between HC- 0.25 and PC, which may be due to the fiber characteristics, which can influence the concrete's fresh density, because the diameter of polypropylene fibers is larger than that of hemp fibers. 


\section{3. The porosity}

The variation of porosity as a function of fiber content for hemp concretes is shown in Figure 4. It varies between 4.83 and $6.41 \%$, and the ordinary concrete (OC) is still the less porous concrete, with the HC- 0.5 concrete being the most porous. The total porosity increases in the case of 0.25 and $0.5 \%$ hemp concentration and decreases for $1 \%$ concentration of hemp fibers. Previous research studies on concretes reinforced with other vegetable fibers confirm those results $[50,51,52,53]$, except for the $1 \%$ dosage. This exception can be the result of poor dispersion of hemp fibers in the concrete for additions higher than $0.5 \%$. Above this value, hemp balls are formed causing heterogeneous parts in the cement matrix and preventing water from entering some parts of the composite, therefore making it less porous.

The increase in porosity is related to: (1) the initial porosity of the natural fibers, (2) the porosity of the cementitious matrix, and (3) the interfacial transition zone (ITZ) around the fibers. The ITZ would be formed during the mixing due to the high water absorption coefficient of the natural fibers. This phase will induce a movement of water from the paste in the fresh state towards the fibers and then yield to a higher porosity during the dry state [50, 52, 54, and 55]. The increase in the porosity value of the PC concretes compared to HC- 0.25 concretes is probably due to the size of the polypropylene fiber being larger than the hemp fiber.

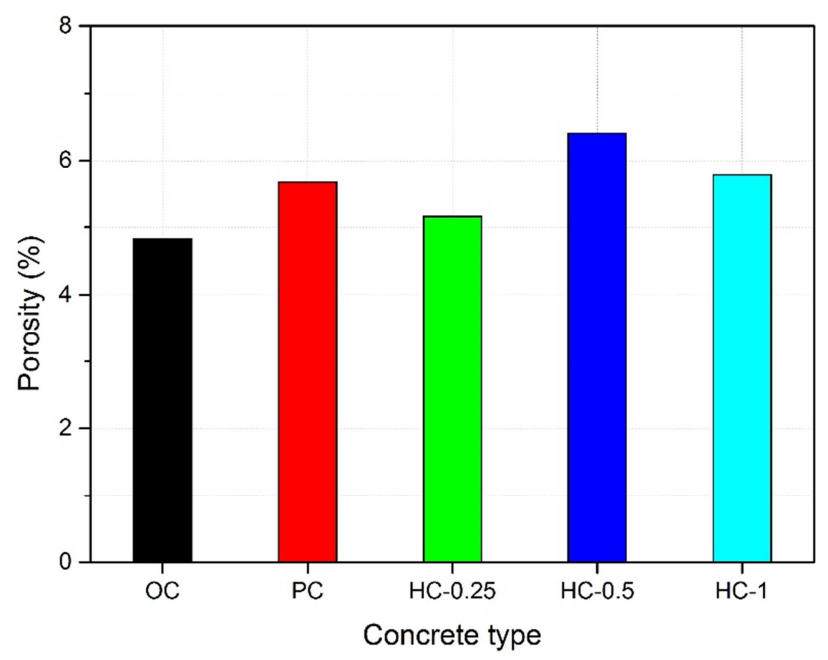

Fig 4. Porosity test results of made-up concretes 


\section{4. Measurement of capillary water absorption}

Capillary absorption is one of the main mechanisms for transferring water and water vapor into concrete [51]. Figures 5 and 6 show the evolution of water absorption and the absorption kinetics of the concrete samples as a function of the hemp fiber content after 24 hours of submersion. From the obtained results, a significant increase in water absorption and absorption kinetics can be observed for HC- 0.25 concretes, which increases with the hemp content. This behavior is due to the followings physical characteristics of the fibers and the cement matrix: (1) the high water absorption capacity of the plant fibers caused by their microporous structure, (2) the increase of porosity of the cementitious matrix, especially in the ITZ zone, and (3) the addition of small amounts of excess water during mixing, which generates the formation of additional porosity as indicated in the literature $[54,56]$.

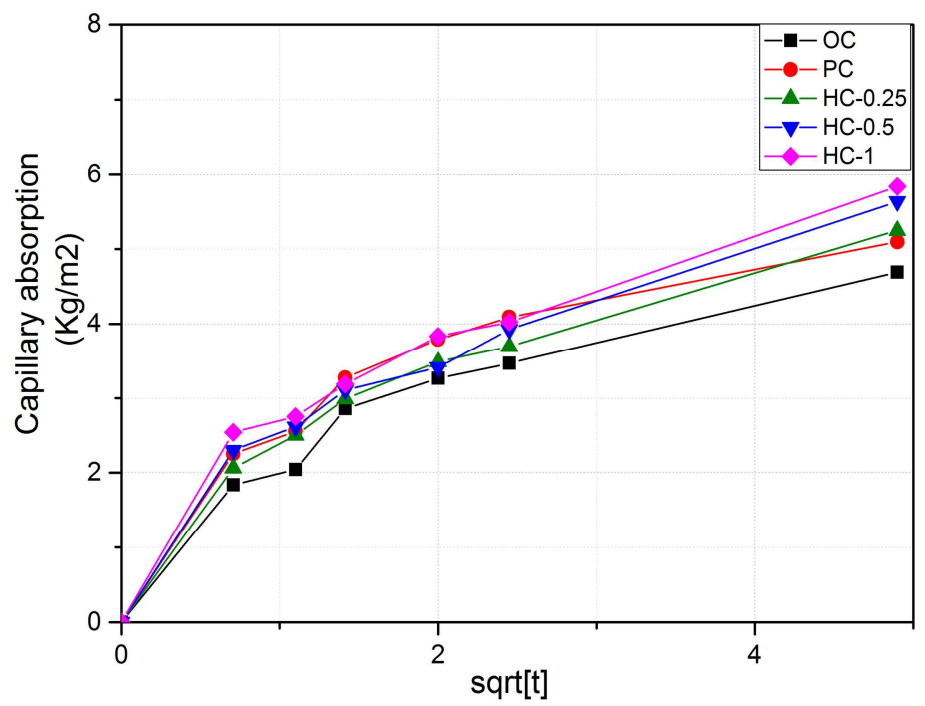

Fig5. Evaluation of the capillary absorption results of made-up concretes 


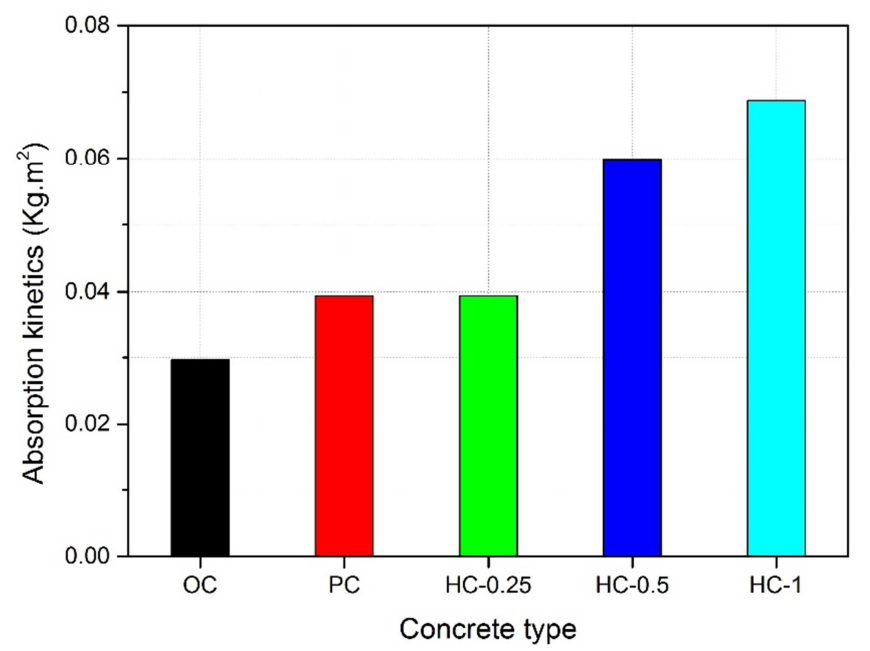

Fig 6. Evaluation of the absorption kinetics results of made-up concretes

On the other hand, a high volume of hemp fibers contributes to increasing the water absorption capacity. Hemp fibers absorb more water, which affects the compressive strength of the concrete and the durability of the composite. It can also be seen that the fiber type has a significant influence on the absorption properties of the composites. Comparing the effect of hemp fibers and polypropylene fibers for the same dosage, the water absorption and absorption kinetics are both higher in the case of polypropylene fiber-reinforced concrete compared to hemp fiber-reinforced concrete, probably due to the larger size of the polypropylene fibers compared to hemp fiber, as explained previously.

\section{5. The compressive strength}

Figure 7 shows the compressive strength of the studied concretes after 7, 28, 90, and 120 days of hardening. The highest compressive strength is observed for OC and the lowest for $\mathrm{HC}-0.5$ and $\mathrm{HC}-1$, which are identical. HC-0.25 shows approximately the same compressive strength as PC. This result shows a relationship between hemp fiber content and compressive strength; the higher the hemp fiber content, the lower the compressive strength, which is estimated at $11.93 \%, 35.73 \%$, and $37.26 \%$, respectively for $\mathrm{HC}-0.25$, HC- 0.5 , and $\mathrm{HC}-1$ compared to OC in 120-day curing. Only HC-0.25 remains within the range of structural concrete. Up to 28 and 120 days, no significant difference is noted between the compressive strengths for each mix. The decrease in compressive strength is due to the creation of a large number of pores due to the poor distribution of fibers in the cement matrix. As the fiber content increases, the cohesion of the composites decreases while the porosity increases, resulting in a considerable reduction in compressive strength. This is confirmed by the 
literature on vegetable fiber reinforced concrete [25, 45, 46, and 57]. It is noted that there is no significant difference between the compressive strengths of PC and $\mathrm{HC}-0.25$ and these results confirm that HC- 0.25 is the best mix using untreated hemp fibers and can substitute polypropylene fibers to give a concrete with both an ecologically sound structure and sufficient strength.

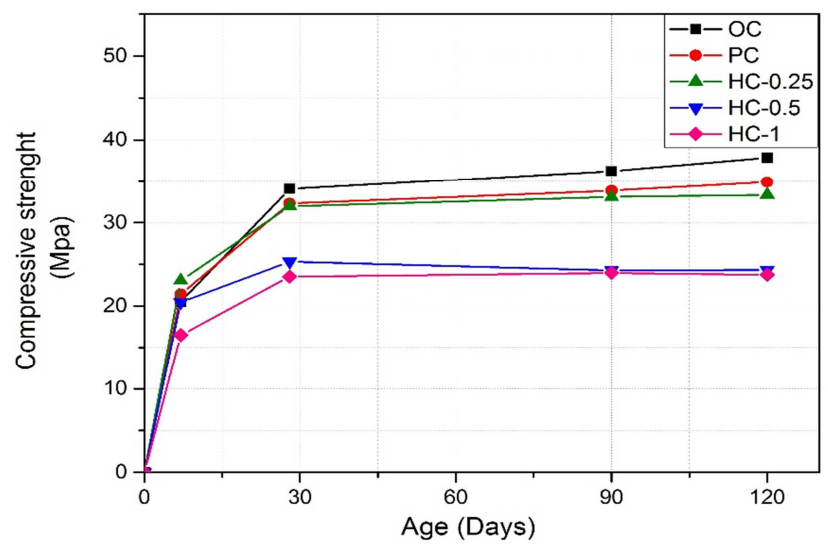

Fig7. Evaluation of compressive strength of made-up concretes

\section{6. The flexural tensile strength}

Figure 8 displays the variations in the flexural tensile strength of concrete as a function of the hemp fiber content after 7, 28, 90, and 120 days of curing. According to Figure 8, the flexural tensile strength of hemp fiber-reinforced concrete shows a significant increase of $21.75 \%$ at a concentration of $0.25 \%$, a slight increase of $3.12 \%$ at a concentration of $0.50 \%$, and a significant decrease of $21.13 \%$ at a concentration of $1 \%$, compared to the reference concrete OC.

For further clarification, Figure 9 shows the comparison of flexural tensile strength under test conditions between OC concrete (Figure 9a) and HC-0.25 concrete (Figure 9b). The increase in flexural tensile strength for HC-0.25 is justified by the mechanical characteristics of the fiber, which once incorporated into the mix, limits the propagation and progression of cracks by a stitching effect (Figure 9c). This situation is confirmed by the bibliography for other types of vegetable fibers [46, 57, and 58]. On the other hand, the decrease in bending tensile strength for $\mathrm{HC}-1$ is due to the concentration of fibers incorporated in the composite. The agglomeration phenomenon is favored in this case, which will generate zones with a cluster of non-adhesive fibers in the cementitious matrix. This behavior is probably due to the effect of the superposition of two potential phenomena; the effect of the fibers not uniformly dispersed in the matrix and the weakening of the cementitious matrix caused by the creation of voids and volume reduction in the cement. 
It should be noted that the use of low percentages of hemp fibers (HC-0.25) offers a tensile strength practically identical to that of PC. These findings again confirm that HC- 0.25 concrete is the optimal hemp fiber-reinforced concrete.

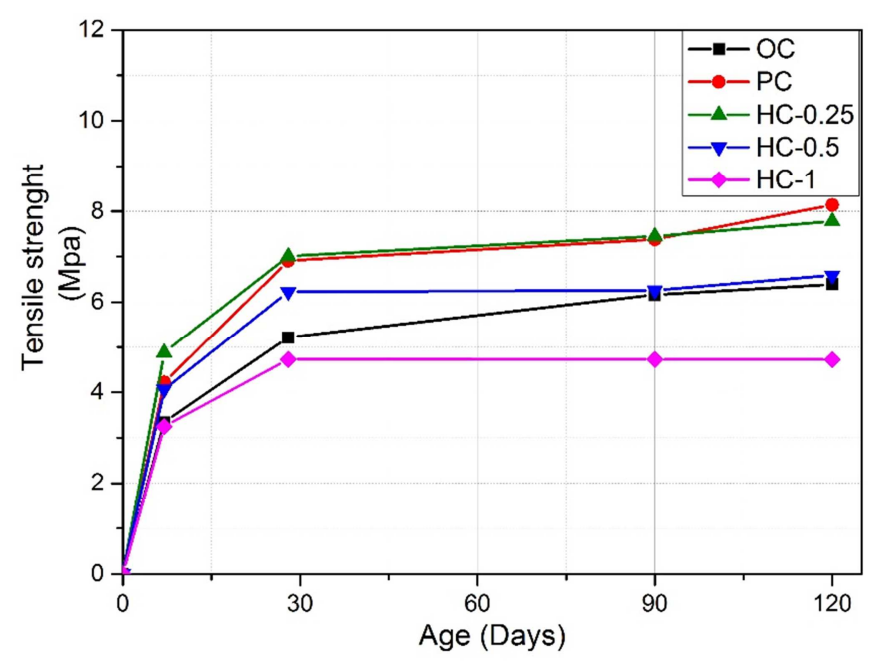

Fig 8. Evaluation of tensile strength of made-up concretes

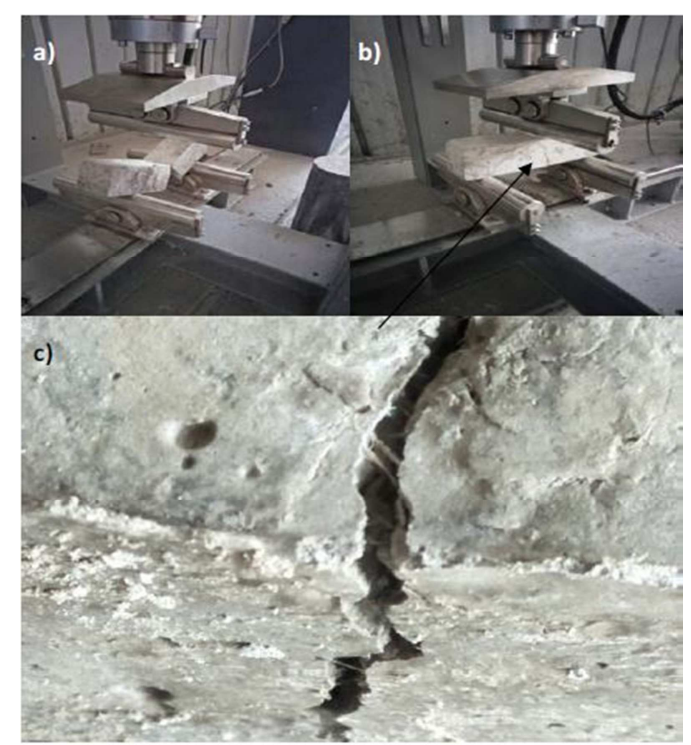

Fig 9. Flexural bending test condition: a) Total spalling of OC sample; b) partial spalling of HC-0.25 sample; c) stitching effect of hemp fibers 


\section{7. The dynamic modulus of elasticity}

Figure 10 presents the results of the dynamic modulus of elasticity. The results show that the incorporation of hemp fibers into the concrete led to a decrease in its dynamic elastic modulus. This decrease is proportional to the fiber content; $5.60 \%$ for $\mathrm{HC}-0.25,11.20 \%$ for $\mathrm{HC}-0.5$, and $15.94 \%$ for $\mathrm{HC}-1$ compared to OC. It reduces the stiffness of the concrete and increases its ductility. The higher the fiber content, the more porous the material $[58,59]$.

On the other hand, it can be seen that the dynamic modulus of elasticity decreases for HC-0.25 compared to PC, which can be explained by the high porosity of PC due to the diameter of the polypropylene fibers, which is larger than that of the hemp fibers.

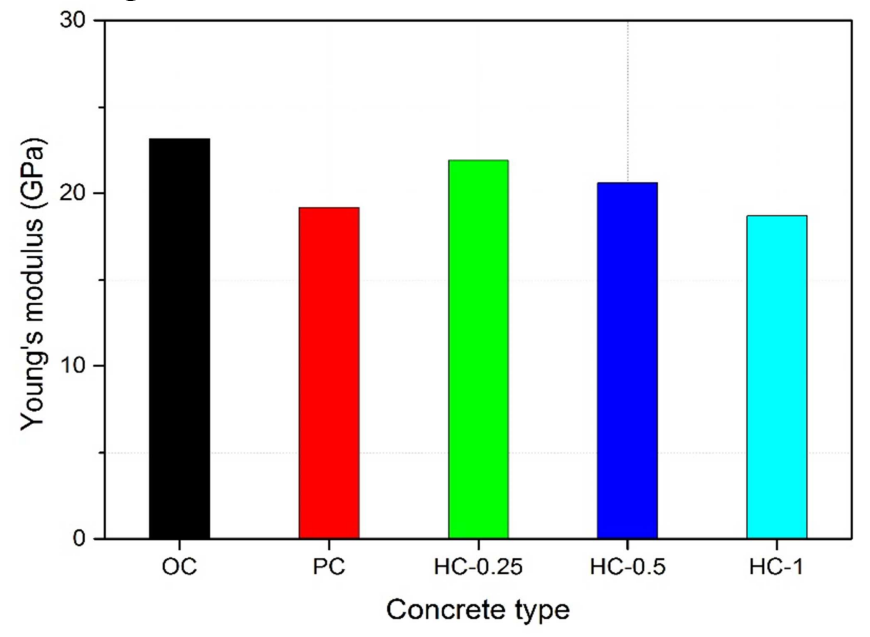

Fig 10. Evaluation of dynamic modulus of elasticity of made-up concretes

\section{8. Sulfatic attack results}

The sulfatic attack protocols were conducted for OC, PC, HC-0.25, and HC- 0.5 mixtures. HC-1 was not included because, as previously described, the objective of the first stage of the experimental program was to select the range of hemp fiber concentration that gives the optimal performance. Thereafter, it was apparent that a concentration of hemp fibers over $0.5 \%$ does not allow any higher performance. In addition, this higher concentration of fibers (over $0.5 \%$ ) generates numerous areas with clusters of non-adhesive fibers within the cementitious matrix which further affects the performance. The results of the sulfatic attack protocols are shown and discussed below. 


\subsubsection{Complete immersion}

\section{- Mass monitoring:}

Figure 11 shows the evolution of mass monitoring as a function of the complete immersion time of the four concrete samples. We observe that the OC and HC0.25 samples behave in an identical way, with a mass gain of about $3 \%$ after 9 months of immersion. Contrary to the HC- 0.5 concrete, this presents a significant mass gain compared to other concretes from $0-75$ days, followed by a mass loss from 75 to 120 days before stabilization until the end of the protocol, with a mass setting of about $1 \%$.

This behavior could be due to the high content of hemp fibers that form balls with non-homogeneous distribution in the matrix, reducing the strength of the concrete. PC concrete behaves almost identically to OC and HC- 0.25 concretes but with a slightly lower mass set than HC-0.25, probably due to the higher fiber content as well as the fiber characteristics. It can be deduced from this that the weight gain is related to the matrix porosity as well as the fiber porosity.

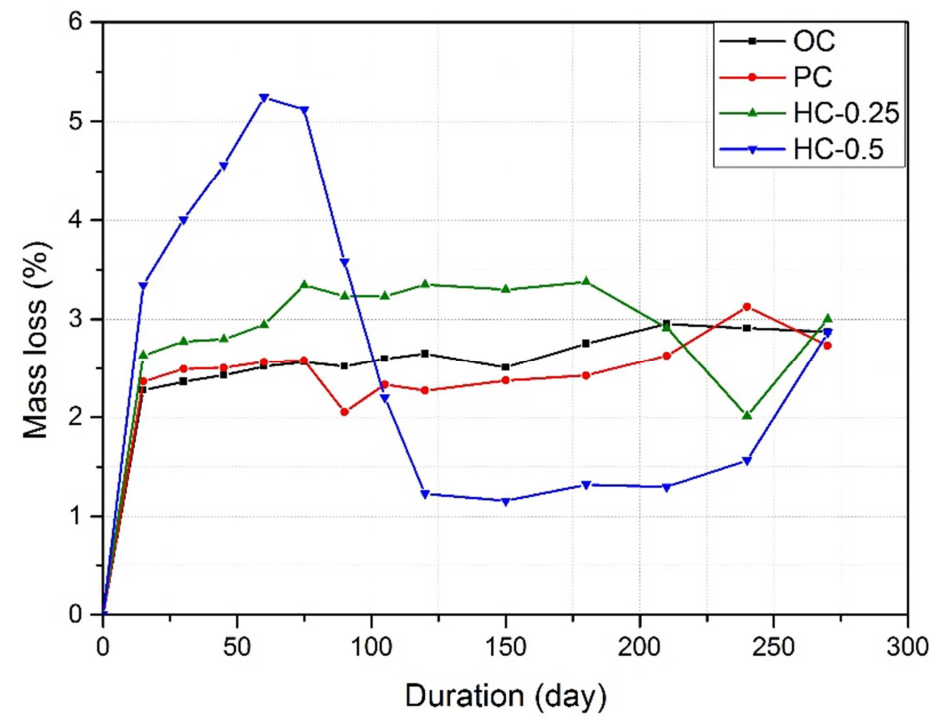

Fig11. Mass monitoring of made-up concretes under sulfatic attacks (complete immersion)

- The variation of the compressive strength:

Figure 12 shows the compressive strength as a function of the complete immersion time of the four concrete samples. It can be seen that from 0 to 45 days, the compressive strengths of PC and OC concretes increase by $8.06 \%$ and $14.54 \%$, respectively, while they decrease slightly for the two hemp fiberreinforced concretes HC- 0.25 and $\mathrm{HC}-0.5$ by $1.75 \%$ and $3.36 \%$, respectively. 
After this, the trend reverses slightly between 45 and 90 days for these two concretes, being $8.60 \%$ for $\mathrm{HC}-0.25$ and $7.32 \%$ for $\mathrm{HC}-0.5$. The $\mathrm{OC}$ and $\mathrm{PC}$ concrete remain almost stable with no significant change.

Between 90 and 180 days, the compressive strengths of the different concretes exposed to full immersion increase progressively and in a continuous manner after the end of this protocol, except for HC-0.5 which continues to decrease, this behavior is linked to the concentration of hemp fibers in the matrix, which affects its compressive strength.

At the end of this protocol, the best compressive strength after 9 months of immersion in sodium sulfate is obtained for concrete reinforced with polypropylene fibers, followed by concrete with $0.25 \%$ hemp fibers, which still has good strength for structural concrete.

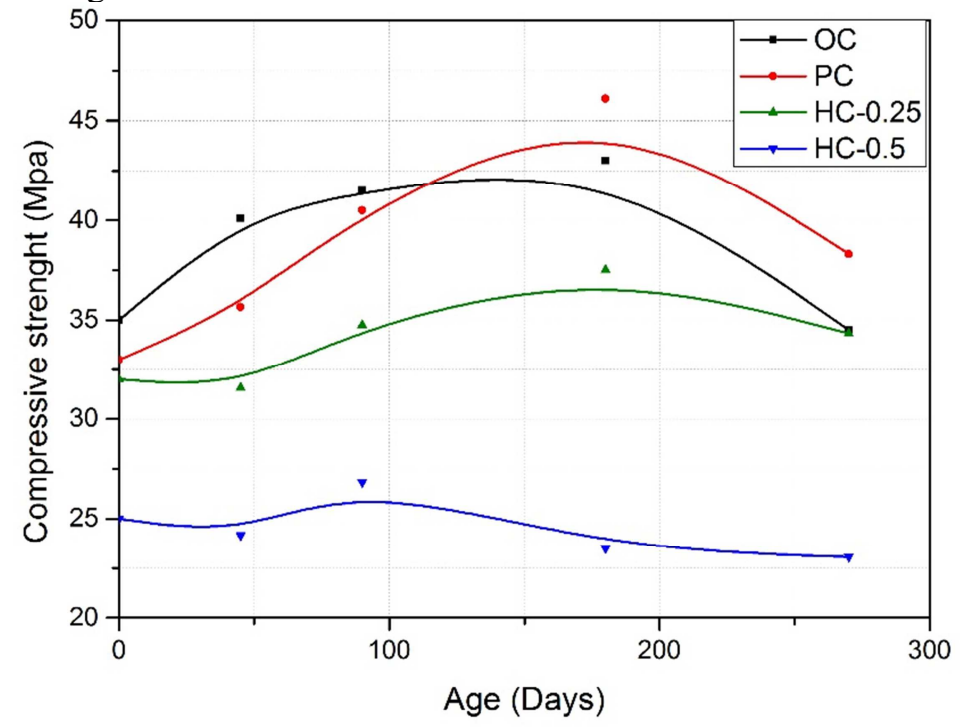

Fig 12. Evolution of compressive strength during sulfatic attacks (complete immersion)

- The macroscopic monitoring:

There was no evidence of sulfate attacks sufficient to cause damage visible to the naked eye in all samples exposed for 9 months to immersion in sodium sulfate (Figure 13). 


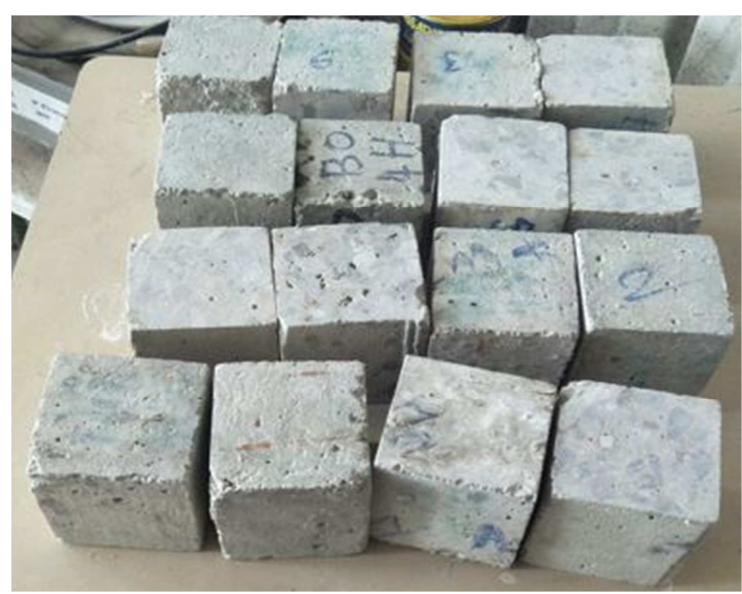

Fig 13. Photo of samples just after release from the sulfatic attacks (case of complete immersion)

\subsubsection{Immersion drying cycles at $60^{\circ} \mathrm{C}$ results}

- The mass monitoring:

Figure 14 shows the evolution of mass monitoring for all concretes. All curves follow the same trend for all concretes. Between 0 and 60 cycles, all concretes have 2 to $3 \%$ mass gain which is interpreted as the result of salt crystallization and trapping of solution within the porosity of the concrete, except that HC-0.5 had a $1 \%$ gain in mass then suffered a sudden loss of mass due to the detachment of several pieces of concrete as well as a pronounced desquamation on several surfaces, causing the ruin of the samples due to the high concentration of hemp fibers which absorb more chemical solution and less cementitious matrix. The result is a rapid degradation of the concrete.

The HC- 0.25 and PC concretes have a very similar behavior towards mass monitoring. Finally, HC-0.25 records the largest increase in mass gained, followed by $\mathrm{PC}$ and $\mathrm{OC}$ which record a final mass gain of $3 \%$ and $2 \%$, respectively. 


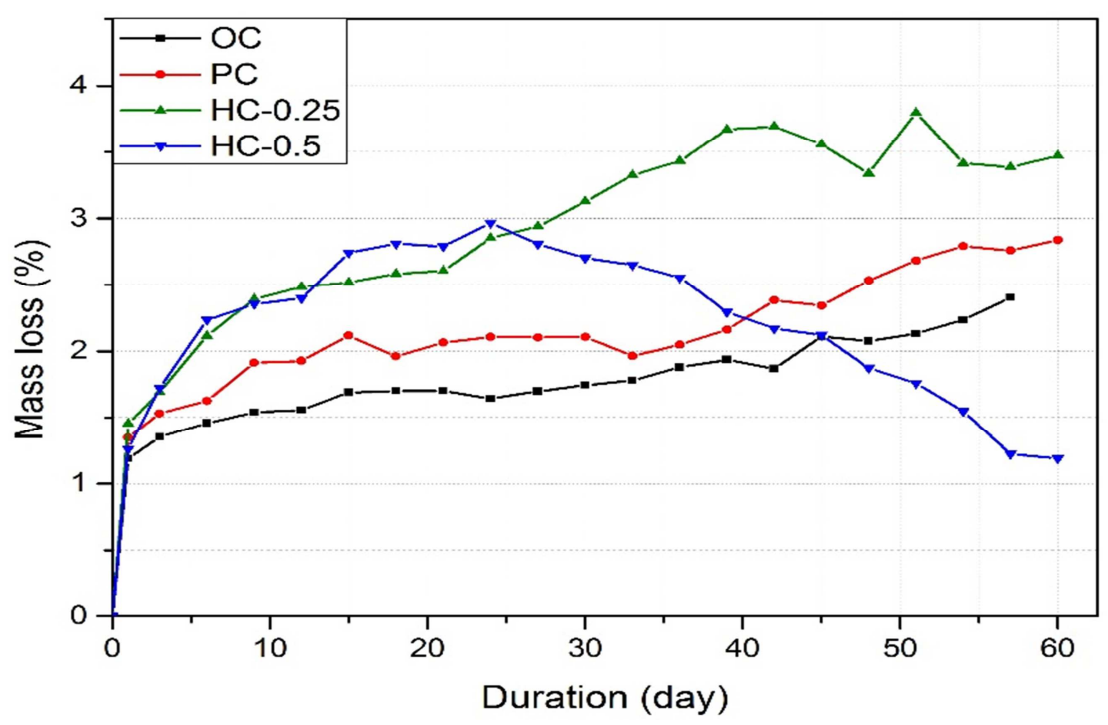

Fig 14. Mass monitoring of made-up concrete sulfatic attacks (Immersion drying cycles at $60^{\circ} \mathrm{C}$ )

- Variation in compressive strength:

Figure 15 shows the evolution of compressive strengths of all the concretes studied at zero (0), five (5), fifteen (15), thirty (30), and sixty (60) cycles of immersion / drying cycles. In general, it can be seen that compressive strength increases starting from zero to 15 cycles, which can be explained by the crystallization of salts in the porosity of the concrete [60], which reinforces the structure.

It is observed that the evolution of the compressive strength of PC and HC-0.25 is similar; a first stage of 0 to 5 cycles where the resistances increase, followed by a slight drop in resistances from 5 to 15 days, and then a further increase in resistance from 15 to 60 days, even if that of the concrete reinforced with polypropylene fibers is more important. HC- 0.25 concrete shows visible signs of failing after 45 days. HC- 0.5 is the concrete most affected by external sulfatic attack at 60 cycles, which can be explained by the high concentration of hemp fibers in the matrix which degrade faster due to the high absorption of chemical solution, causing rapid formation of expansive products in the matrix which leads to serious damage to the concrete.

Figure 14 also shows the mass increment, meaning less porosity, and Figure 15 specifies for concretes reinforced with hemp fibers a universal reduction in 
compressive strength. This observation was due mainly to the rapid absorption of the solution by the natural fibers in comparison with the synthetic fibers, which results in a mass increase and at the same time will produce a degradability of natural fibers and a decrease in the mechanical performance of the made-up concretes. These observations are similar to findings in the case of Alfa fiber-reinforced concrete [14].

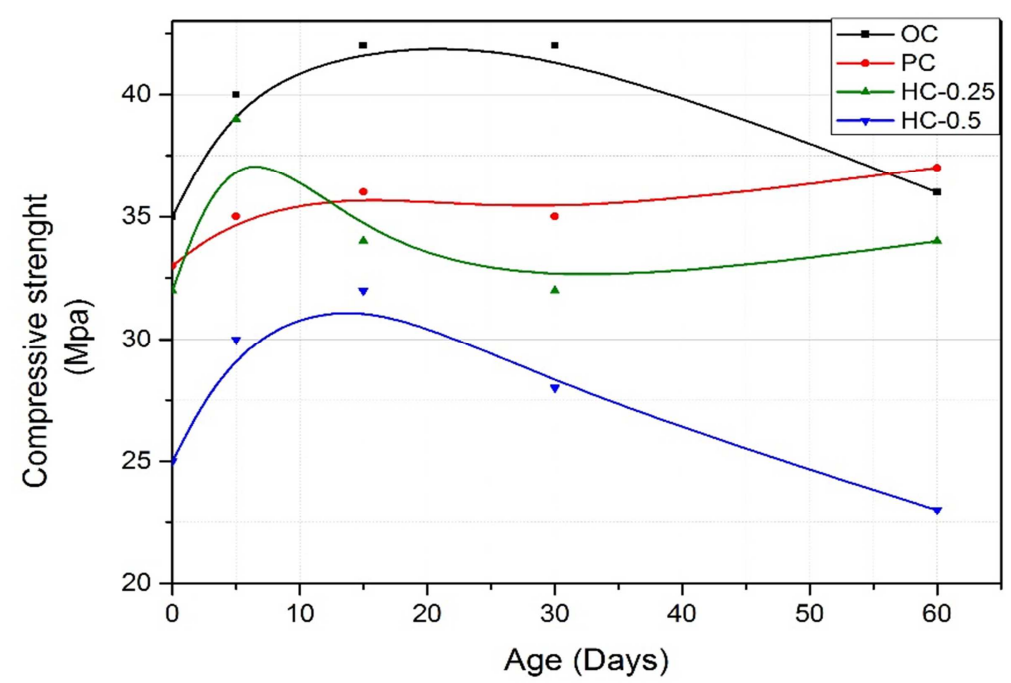

Fig15. Evolution of compressive strength during sulfatic attacks (Immersion drying cycles at $60^{\circ} \mathrm{C}$ )

- The macroscopic monitoring:

During 60 days of this experimental protocol, photographs were taken regularly before and after immersion, thus providing visual information on the macroscopic evolution of the samples as well as the appearance of possible damage (Figure 16).

Significant degradations were observed in the $0.25 \%$ (HC-0.25) and $0.5 \%$ (HC$0.5)$ hemp fiber-reinforced concrete. The degradations are important in the case of HC-0.5, which contains a high concentration of hemp fibers. Vegetable fibers seem to play a role in absorbing the solution, which does not allow crystallization on the surface, while concrete reinforced with polypropylene (PC) fibers did not show any symptoms of degradation or efflorescence caused by salts. 

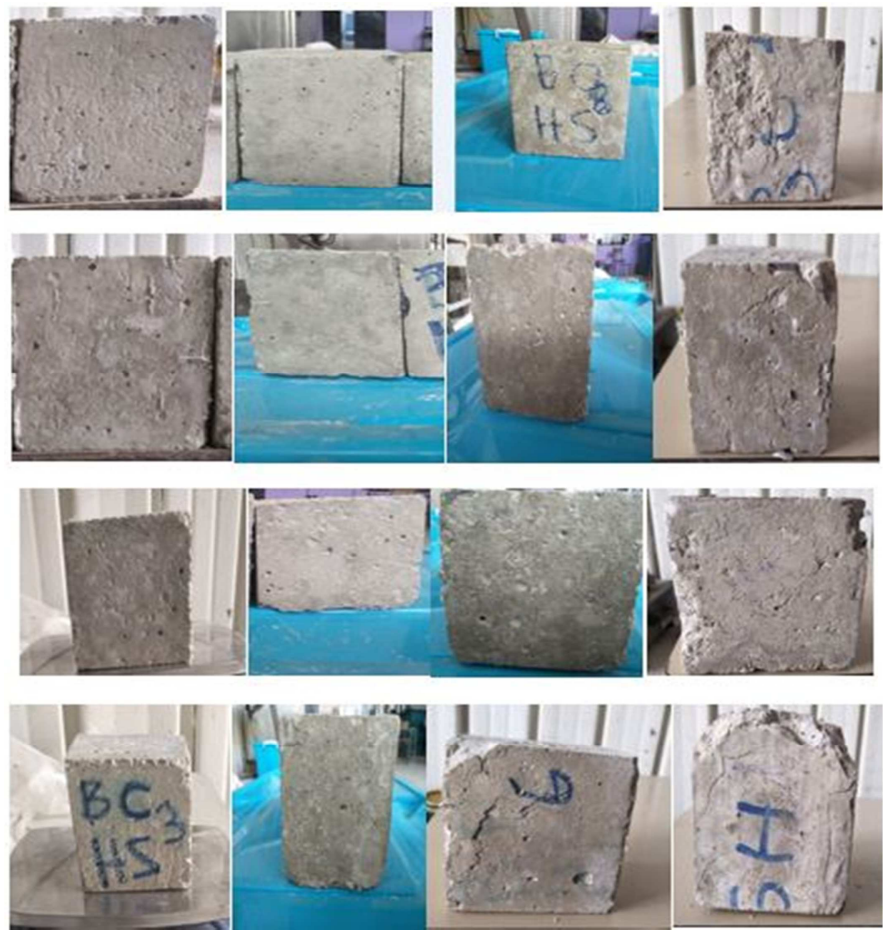

Fig16. Photos of samples just after release from the sulfatic attacks (Immersion drying cycles at $60^{\circ} \mathrm{C}$ )

\section{CONCLUSION}

Based on the presented results, the following conclusions can be summarized:

- The addition of hemp fibers negatively affects the workability of the concrete. This situation can be explained by the high water absorption and the specific surface of the natural fiber. It also affects the concrete density in the fresh state by causing poor compaction which induces the creation of pores and the formation of water-conducting channels, thereby increasing the water absorption of the concrete.

- Hemp fibers do not improve the compressive strength of concrete, which decreases when the addition exceeds $0.25 \%$ due to the heterogeneous dispersion of the fibers in the form of balls.

- Hemp fibers improve the tensile strength of concrete, which is higher than the ordinary concrete and closer to the concrete reinforced with polypropylene fibers. This property could prevent the rapid spread of cracks in concrete and the sudden ruin of buildings. 
- The addition of fibers in concrete, whether synthetic or natural, negatively affects the dynamic modulus results. In addition, increasing the percentage of fibers will result in lower dynamic modulus values. Nevertheless, the results for hemp fiber-reinforced concretes are better than those for concrete with polypropylene fibers.

- Hemp fibers considerably reduce the granular compactness in concrete, due to the poor dispersion of the fibers. The inclusion of Hemp fibers, especially with a concentration over $0.5 \%$, leads to the forming of masses with a cluster of non-adhesive fibers in the cementitious matrix which prevent the hydration and homogenization process of the mixture, therefore, they contribute to increasing the total porosity, which could affect the compressive strength.

- The use of hemp fibers in concrete reinforcement with a percentage higher than $0.25 \%$ increases the capillary absorption and absorption kinetics, making the concrete more vulnerable and therefore exposing it to possible alteration.

- No visible damage (cracking and swelling) was observed for concretes (OC, HC-0.25, HC-0.5, and PC) despite a decrease in compressive strength at the end of the full immersion protocol. In addition, there was no evidence of external sulphatic attack, which is consistent with previous work on vegetal fiber-reinforced concrete [14].

- The visible degradation of HC-0.25 and HC-0.5 samples is due to the probable formation of secondary ettringite. The HC- 0.5 samples are the most altered in protocol immersion drying because of the high concentration of fibers. In addition, HC- 0.25 remains the reference fiber concrete because it is more efficient compared to HC-0.5 and offers the optimal resistance at the end of the protocol.

Overall, structural concrete reinforced with $0.25 \%$ of untreated hemp fibers 20 $\mathrm{mm}$ in length, appears to be an eco-friendly product compared to concrete reinforced with polypropylene fibers since hemp fibers are neither treated nor manufactured in factories and polypropylene fibers are derived from petroleum. This concrete gives the optimal mechanical results and fulfills the conditions to be a more durable facing for resisting external sulfatic attacks. 


\section{REFERENCES}

1. Afroughsabet,V, Luigi Biolzi and Paulo JM Monteiro 2018. The effect of steel and polypropylene fibers on the chloride diffusivity and drying shrinkage of high-strength concrete, Composites Part B 139, 84-96.

2. Simões, TH, Costa, D, Dias-da-Costa and E, Júlio 2017. Influence of fibers on the mechanical behavior of fiber-reinforced concrete matrixes. Construction and Building Materials 137, 548-556.

3. Lee, JH, Baiksoon Cho, Eunsoo Choiand Yong-Hyung Kim 2016. Experimental study of the reinforcement effect of macro-type high strength polypropylene on the flexural capacity of concrete. Construction and Building Materials 126, 967-975.

4. Zhang, M, Chen, J, Lv, Y, Wang, D and Ye,J 2013. Study on the expansion of concrete under attack by sulfate and sulfate-chloride ions. Construction and Building Materials 39, 26-32.

5. Secco, J, Giulio Isacco Lampronti, Moritz-Caspar Schlegel, Maritan, L and Zorzi, F 2015. Degradation processes of reinforced concretes by combined sulfate-phosphate attack. Cement and Concrete Research 68, 49-63.

6. Lothenbach, B, Bary, B, Le Bescop, P, Schmidt, Th, N, Leterrier, 2010. Sulfate ingress in Portland cement. Cement and Concrete Research 40, $1211-1225$.

7. El-Hachem, RE, Rozière, F and Grondin, A. Loukili 2012. New procedure to investigate external sulphate attack on cementitious materials. Cement \& Concrete Composites 34, 357-364.

8. Müllauer, W, Beddoe, R and Heinz, D 2013. Sulfate attack expansion mechanisms. Cement and Concrete Research 52, 208-215.

9. Karahan, O and Duran Atis, C 2011. The durability properties of polypropylene fiber-reinforced fly ash concrete. Materials and Design 32, 1044-1049.

10. Arslan, MA 2016. Effects of basalt and glass chopped fibers addition on fracture energy and mechanical properties of ordinary concrete: CMOD measurement. Construction and Building Materials 114, 383-391.

11. Kuder, KG and Shah, SP 2010. Processing of high-performance fiberreinforced cement-based composites. Construction Building Materials $\mathbf{2 4}$ (2), 181-186.

12. Soylev, TA and Ozturan, T 2014. Durability, physical and mechanical properties of fiber-reinforced concretes at low-volume fraction. Construction and Building Materials 73, 67-75.

13. Grubeša, IN, Markovic, B, Gojevic, A and Brdaric, J 2018. Effect of hemp fibers on fire resistance of concrete. Construction and Building Materials 184, 473-484. 
14. Ziane, S, Khelifa, MR, Mezhoud, S and Medaoud, S 2020. Durability of concrete reinforced with alfa fibres exposed to external sulphate attack and thermal stresses. Asian Journal of Civil Engineering.

15. Hsie, M, Tu, C and Song, PS 2008. Mechanical properties of polypropylene hybrid fiber-reinforced concrete. Materials Science and Engineering A 494, 153-157.

16. Charlet, K, Baley, C, Morvan, C, Jernot, JP, Gomina, M and Bréard, J 2007. Characteristics of Hermès flax fibres as a function of their location in the stem and properties of the derived unidirectional composites. Composites Part A: Applied Science and Manufacturing 38, 1912- 1921.

17. Kakooei, S, Md Akil, H, Jamshidi, M and Rouhi, J 2012. The effects of polypropylene fibers on the properties of reinforced concrete structures. Construction and Building Materials 27, 73-77.

18. Shah, S, Swartz, S and Ouyang, C 1995. Fracture mechanics of concrete: applications of fracture mechanics to concrete, rock, and other quasi-brittle materials. Wiley- Interscience.

19. Wei, J and Meyer,Ch 2015. Degradation mechanisms of natural fiber in the matrix of cement composites. Cement and Concrete Research 73, 1.

20. Merta, I and Tschegg, EK 2013. Fracture energy of natural fibre-reinforced concrete. Construction and Building Materials 40, 991-997.

21. Pickering, KL, Efendy, MA and Le, TM 2016. A review of recent developments in natural fibre composites and their mechanical performance. Compos Appl Sci Manuf 83, 98-112.

22. Hamza, S, Saad, H, Charrier, B, Ayed, N and Charrier-El Bouhtoury, F 2013. Physicochemical characterization of Tunisian plant fibers and its utilization as reinforcement for plaster based composites. Industrial Crops and Products 49, 357-365.

23. Shahzad, A 2012. Hemp fiber and its composites-a review. J. Compos. Mater 46, 973-986.

24. Zampori, L, Dotelli, G and Vernelli, V 2013. Life cycle assessment of hemp cultivation and use of hemp-based thermal insulator materials in building. Environmental Science \& Technology 47, 7413-7420.

25. Wang, $\mathrm{H}$ 2002. Design and optimisation of chemical and mechanical processing of hemp for rotor spinning and textile applications, $\mathrm{PhD}$ Thesis. University of New South Wales.

26. Li, Z, Wang, $X$ and Wang, L 2006. Properties of hemp fibre-reinforced concrete composites. Composites Part A 37 (3), 497-505.

27. Li, Z, Wang, L and Wang, X 2004. Compressive and flexural properties of hemp fiber-reinforced concrete. Fibers Polym. 5 (3), 187-197. 
28. Khelifa, MR 2009. Effet de l'attaque sulfatique externe sur la durabilité des bétons autoplaçants, Thèse de doctorat en Génie Civil, Ecole Polytechnique de l'Université d'Orléans.

29. Molez, L, Bian, H and Prince-Agbodjan, W 2012. Résistance au gel/ dégel des BFUHP: Compétition entre endommagement et cicatrisation. Chambéry, Savoie: XXXe Rencontres de l'AUGC-IBPSA.

30. Chamoin, J 2013. Optimisation des propriétés (physiques, mécaniques et hydriques) de bétons de chanvre par la maitrise de la formulation, $\mathrm{PhD}$ Thesis. INSA Rennes.

31. Niyigena, C 2016. Variabilité des performances de bétons de chanvre en fonction des caractéristiques de la chènevotte produite en Auvergne, $\mathrm{PhD}$ Thesis Universite Blaise Pascal-Clermont II.

32. Sedan, D, Pagnoux, C, Smith, A and Chotard, T 2008. Mechanical properties of hemp fiber-reinforced cement: Influence of the fibre/matrix interaction. Journal of the European Ceramic Society 28, 183-192.

33. NF EN 197-1 (2000). Cement - part 1: Compositions. Specifications and conformity criteria for common cement. Brussels: European Committee for Standardization.

34. NF EN 934-2 (2012). Adjuvants pour bétons, mortier et coulis - Partie 2 : adjuvants pour béton - Définitions, exigences, conformité, marquage et étiquetage.

35. NF EN 12350-2 Avril (2012). Essais pour béton frais - Partie 2 : essai d'affaissement [Testing fresh concrete - Part 2: Slump test], in french.

36. NF EN 12350-6 Avril (2012). Essais pour béton frais - Partie 6 : masse volumique, French: AFNOR.

37. NF P 15-471. Essais des Bétons - Essais Destructifs, Norme Française homologuée.

38. NF P 18-414 (1993). Essais des Bétons - Essais Non Destructifs. Mesure de la Fréquence de Résonance Fondamentale [Testing of concrete - nondestructive testing - Measurement of the fundamental resonance frequency]. French: AFNOR.

39. AFPC-AFREM (1997). Recommended methods for measuring of durability parameters. Proceedings of the technical AFCP/AFREM days on concrete durability, Toulouse (pp.125-134). 11 and 12 December.

40. Ghrici, M, Kenai, S and Meziane, E 2006. Mechanical and durability properties of cement mortar with algeria, natural pozzolana. Journal of Materials Science 41(21), 6965-6972.

41. Kevin, B 2006. Etude des propriétés hydriques et des mécanismes d'altération de pierres calcaires à forte porosité, Thèse de doctorat en Sciences des Matériaux, Université d'Orléans. 
42. Brunetaud, X 2005. Etude de l'influence des différents paramètres et leurs interactions sur la cinétique et l'amplitude de la réaction sulfatique interne au béton, Thèse de doctorat en Physicochimie des Matériaux, Ecole Centrale de Paris.

43. Brunetaud, X, Linder, R, Divet, L, Duragrin, D and Damidot, D 2007. Effect of curing conditions and concrete mix design on the expansion generated by delayed ettringite formation. Materials and Structures 40(6), 567-578.

44. Lane, DS and Ozyildirim, HC 1999. Evaluation of the potential for internal sulfate attack through adaptation of ASTM C 342 and the Duggan test. Cement. Concrete and Aggregates 21(1), 43-58.

45. Khelifa, MR, Leklou, N, Bellal, T, Hebert, RL and Ledesert, AB 2016. Is alfa a vegetal fibre suitable for making green reinforced concrete? European Journal of Environmental and Civil Engineering pp. 1-21.

46. Page, J, Khadraoui, F, Boutouil, M and Gomina, M 2017. Multi-physical properties of a structural concrete incorporating short flax fibers. Construction and Building Materials 140, 344-353.

47. Okeola, A, Abuodha and Mwero, J 2018. Experimental Investigation of the Physical and Mechanical Properties of Sisal Fiber-Reinforced Concrete, Fibers 6, 0053.

48. Aziz, MA, Paramasivam, P and Lee, SL 1981. Prospects for natural fibrereinforced concretes in construction. Int. J. Cem. Compos. Lightweight Concr. 3, 123-132.

49. Bentur, A 2007. Fibre-reinforced cementitious composites, 2nd Edition, Taylor \& Francis, London; New York.

50. Daya, A, Langlet, E, Benazzouk, T and Quéneudec, AM 2008. Feasibility study of lightweight cement composite containing flax by-product particles: Physico-mechanical properties. Cement and Concrete Composites 30, 957963.

51. Xie, X, Zhou, Z and Jiang, M 2015. Cellulosic fibers from rice straw and bamboo used as reinforcement of cement-based composites for remarkably improving mechanical properties. Compos Part B: Eng. 78, 153-161.

52. Achour, A, Fouad Ghomari and Naima Belayachi 2017. Properties of cementitious mortars reinforced with natural fibers, Journal of Adhesion Science and Technology.

53. Carrillo, J, Ramirez, J and Lizarazo-Marriaga, J 2019. Modulus of elasticity and Poisson's ratio of fiber-reinforced concrete in Colombia from ultrasonic pulse velocities. Journal of Building Engineering 23, 18-26.

54. Savastano, H et al. 1999. Plant fibre-reinforced cement components for roofing. Constr Build Mater. 13, 433-438. 
55. Magniont, $\mathrm{C} 2010$. Contribution to the formulation and characterization of an eco-building material based on agricultural resources, $\mathrm{PhD}$ Thesis in Civil Engineering. Toulouse: Toulouse University.

56. Shoukry, $\mathrm{H}$ et al. 2016. Thermo-physical properties of nanostructured lightweight fiber-reinforced cementitious composites. Construction and Building Materials.

57. Kriker, A, Debicki, G, Bali, A, Khenfer, MM and Chabannet, M 2005. Mechanical properties of date palm fibres and concrete reinforced with date palm fibres in hot-dry climate. Cem. Concr. Compos. 27, 554-564.

58. Ali, M 2014. Seismic performance of coconut-fiber-reinforced concrete columns with different reinforcement configurations of coconut-fiber ropes. Construction and Building Materials 70, 226-230.

59. Yan, L and Chouw, N 2014. Dynamic and static properties of flax fibrereinforced polymer tube confined coir fibre-reinforced concrete. J. Compos. Mater. 48 (13), 1595-1610.

60. John, MJ and Anandjiwala, RD 2008. Recent developments in chemical modification and characterization of natural fiber-reinforced composites. Polymer Composite 29, 187-207.

Editor received the manuscript: 06.04.2020 